\title{
The use of metadata systems for the preservation of digital records in cultural heritage institutions
}

\author{
Tlou Maggie Masenya \\ Durban University of Technology \\ tm.masenya@webmail.co.za \\ http://orcid.org/0000-0001-5400-0549
}

Received: 08 May 2020

Revised: 06 April 2021

Accepted: 19 August 2021

\begin{abstract}
Many studies concur that most of the world's heritage resources, including digital records, are highly vulnerable to loss, and some cannot be recovered due to neglect or mismanagement. Strategies are thus needed to ensure long-term preservation and global access to digital records of enduring value. Metadata systems have been regarded as a suitable strategy to support digital preservation processes and prevent digital records loss within cultural heritage institutions. The purpose of this paper was to investigate the adoption of metadata systems in cultural heritage institutions in South Africa. This study utilised literature review to critically examine the use of metadata systems for the preservation of digital records in cultural heritage institutions. Although various preservation systems and strategies are being developed to enable description, discovery and delivery of digital records, the findings revealed that South African cultural heritage institutions' level of metadata system adoption is low. This is due to lack of awareness about metadata schemas and standards, lack of technical expertise, inadequate funding and lack of technological infrastructure. Several recommendations are made to enhance preservation of digital records, including increasing awareness and the implementation of metadata systems, schemas and policies.
\end{abstract}

Keywords: digital preservation, digitisation, digital records, metadata, cultural heritage institutions

\section{Introduction}

Records are the basis for the trust societies should have in their governments and cultural heritage institutions. Like paper records, digital records need to be recorded accurately, serve as the foundation of trust and continue to provide evidence of its activities for as long as they are needed (ICA 2016). Cultural heritage institutions (typically grouped as libraries, archives and museums) are important records custodians and contribute to our national cultural heritage management and preservation. Any digital preservation system's goal is ensuring the information it contains remains accessible to users over a long time (Rosenthal, Robertson, Lipkis, Reich \& Morabito 2005). Digital preservation involves planning, resource allocation and application of preservation 
methods and technologies, and it combines policies, strategies and actions to ensure access to reformatted and born digital content, regardless of the challenges of media failure and technological change (May 2010). Duranti (2010) describes digital preservation as the whole of the principles, policies, rules and strategies aimed at prolonging the existence of a digital object by maintaining it in a condition suitable for use, either in its original format or in a more persistent format, while protecting the object's identity and integrity (its authenticity).

Kalusopa (2018) states the rationale underpinning digital preservation is the need to maintain the ability to display and retrieve digital information in the face of rapidly changing technological and organisational infrastructures. Archival theory recognises the purpose of preservation to be the transmission of records through time and across technological change in such a way they can be presumed authentic and reliable (Duranti, Rogers, Mcleod \& Shepherd 2019). UNESCO's Memory of the World Programme was developed with its mission to facilitate the world's documentary heritage preservation and increase awareness of the existence and significance of documentary heritage (UNESCO 2012). The programme's vision states the world's documentary heritage belongs to all and should be fully preserved, protected and permanently accessible to all without hindrance.

The change to the digital world raises serious issues on how to organise, access and preserve digital records into perpetuity, as created by cutural heritage institutions. The ever-expanding digital resources were produced without much regard to long-term preservation issues (Masenya 2018). Preserving digital records in South African cultural heritage institutions posed challenges to archivists, librarians and other custodians of such materials, like other African countries such as Zimbabwe, Botswana, Nigeria and Ghana (Sigauke \& Nengomasha 2011; Boamah 2014; Ilo 2015; Kalusopa 2018). Digital records are vulnerable to loss and destruction as they are stored on fragile magnetic and optical media which deteriorate rapidly, and they could fail suddenly from use on faulty reading and writing devices (Sambo, Urhefe \& Ejitagha 2017). The Council of Canadian Academies (2015) observed that libraries, archives and museums were facing numerous challenges in attempting to adapt to the digital age, including dealing with rapid technology obsolescence, making accessible mass quantities of digital data and remaining trusted as repositories that hold documentary evidence of scholars and citizens. Dar and Ahmad (2017) note that digital records are inherently software-dependent, regardless of their format, and this poses immense challenges to its long-term preservation.

Cultural heritage institutions are running the risk of losing vital digital information due to technology obsolescence or original software being outdated and incompatible with modern operating systems, absence of accurate and complete metadata, inadequate resources, lack of policies and procedures, and storage media fragility (Masenya 2018). For example, Newham Museum Archaelogical Service in United Kingdom lost some digital data due to technology obsolescence. Simpson (2004) states the digital materials were stored in a variety of proprietary software and versions that are now archaic, and some of these materials became inaccessible. The digital records are threatened by lack of will to invest resources in migration, problems of security and protection of personal data. It is necessary for cultural heritage institutions to adopt long-term digital preservation strategies to preserve digital records perpetually and make them accessible on 
any standard platform. De la Porte and Huggins (2019) concur that a well-planned strategy is needed for institutions to deliver valuable and sustainable preservation of digital heritage. The Online Computer Library Center (OCLC) (2007) developed strategies for the long-term preservation of digital objects, namely:

- Assessing the risks for loss of content posed by technology variables such as commonly used proprietary file formats and software applications.

- Evaluating the digital content objects to determine what type and degree of format conversion or other preservation actions should be applied.

- Determining the appropriate metadata needed for each object type and how it is associated with the objects.

Metadata is the preferred strategy for addressing the problems of hardware, software obsolescense and backup issues (Sambo et al. 2017). Bountouri (2017) describes metadata as information about the objects stored in the collections and its specific functions, including identification of objects, search, retrieval and management of collections, etc. In the current reality of rapidly changing technologies, trust is a problem, and more direct means to establish trust are metadata, logs and audit trails (Duranti et al. 2019). As indicated by ICA (2016), digital records must be reliable, authentic and accessible for as long as they are required, and it is largely through metadata systems that digital records' integrity and trustworthiness can be established.

\section{Problem statement}

Valuable scientific and cultural information assets are created, stored, managed and accessed digitally, but the threat of losing them over the long term is high (Dappert \& Enders 2010). In 2008, students and workshop participants were asked to indicate whether they still have the first photo they took on a cellphone; the response was overwhelming negative (Groenewald \& Breytenbach 2011). With the move from analogue object-based memory to a digital-based memory, cultural heritage institutions are facing new challenges in ensuring our collective cultural heritage is not lost (UNESCO 2012). Chowdhury (2009) identifies a number of digital preservation challenges ranging from increasingly large volumes of data to the underlying hardware, data formats and metadata systems. Technological obsolescence also add risk to continued accessibility and long-term preservation of digital assets (Masenya 2018). Lack of awareness about the historical value and significance of digital heritage among corporate and policy makers has been taken for granted for far too long (Corrado \& Moulaison 2014). The problem of ensuring longterm access to digital records is compounded because most digital objects are not properly organised or do not have proper descriptions (Ross \& Hedstrom 2005).

What should these institutions do to ensure long-term access to their digital records? Styblinska (2006) states ensuring ongoing access requires currency with technological changes and moving digital objects from obsolete to current file formats, storage media and operating systems. Brungs and Wyber (2016) state we will lose our cultural heritage if cultural heritage institutions and all other related stakeholders do not act now, and our times will be a new dark age in history. This underscores the need to develop strategies or workable solutions to digital preservation. Metadata system is regarded as the best way of minimising the risk of digital objects becoming inaccessible. 
Although metadata systems are crucial for preserving the digital objects, the level of its adoption is low in cultural heritage institutions. It is critical to have a deeper understanding of metadata systems in digital preservation processes and to assess the level of their adoption in cultural heritage institutions in South Africa. There is also a need for proper technology infrastructure conforming to metadata and other international standards required to measure and validate the trustworthiness of digital resources in respect of authenticity, integrity and reliability of the digital materials.

\section{Study objectives}

The objectives of this study were to:

- determine the use of metadata systems in preserving digital records

- determine the digital preservation practices in cultural heritage institutions

- establish the barriers to effective adoption of metadata systems in cultural heritage institutions

- determine the existing metadata standards used for digital preservation in cultural heritage institutions.

\section{Conceptual framework}

This study adopted the Metadata Lifecycle Model (MLM) and Open Archival Information System (OAIS) reference model to identify the existing methods and strategies used for digital preservation practices to provide guidelines for the development and implementation of metadata systems within cultural heritage institutions.

\subsection{Metadata Lifecycle Model}

The MLM is a methodology involving a ten-step process by which cultural heritage institutions can design and implement a successful metadata system. This model focuses on managing records through ten stages, as illustrated in Figure 1: 


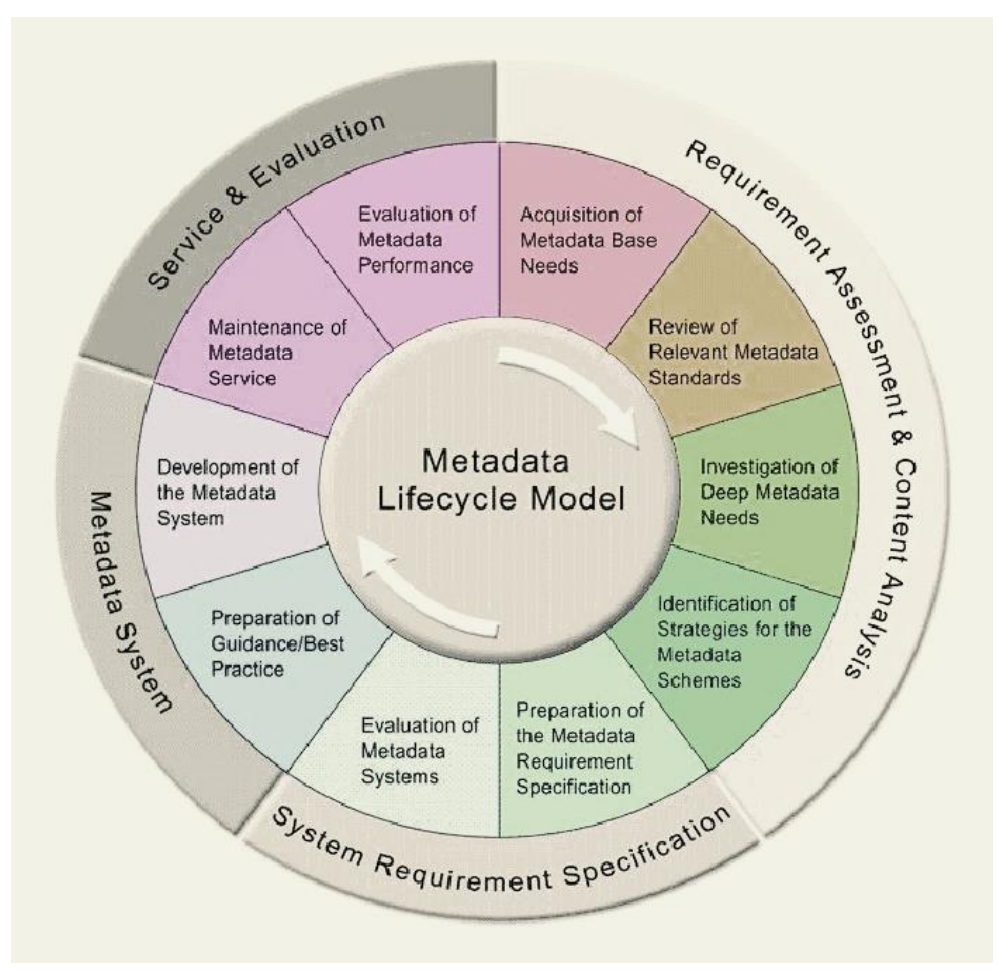

Figure 1: Metadata Lifecycle Model (Chen, Chen \& Lin, 2003)

The ten steps are described by Chen, Chen and Lin (2003), as follows:

- Acquisition of basic metadata needs - the first step is interviewing the content experts or providers about their metadata requirements for each collection project and analysing the attributes of collection projects.

- Assessment of deep metadata needs - content analysis is used to acquire metadata needs through a set of Work Documents (WD) including: WD1: Metadata Element-Name, Definition and Comment; WD2: Metadata Element-Control Vocabulary; WD3: Metadata Element-Example, WD4: Metadata Element-Data Type and WD5: Metadata Element Unique Identifier System.

- Review of metadata standards and projects - this involves identifying and examining the potential metadata standards and schemes whereby the four layers for metadata selection are developed to support the analysis of the collection project attributes.

- Identification of strategies for the metadata schemes - this involves the metadata strategy formulation for the digital archive that usually includes adopting one or several existing metadata standards such as Dublin Core and Machine-Readable Cataloguing 21 (MARC21).

- Preparation of the metadata requirement specification - metadata specialists and system designers prepare a Metadata Requirement Specification (MRS) that should contain the executive summary, background information of the collection project, objectives of the metadata system, statement of adopted metadata standards, structure and related standards mapping (i.e. Dublin Core). 
- Evaluation of metadata systems - the collection project members can select an existing system developed by collection projects at this stage in collaboration with others such as university or industry teams.

- Preparation of best practice and guidance - best practices and guidelines are generated for individual metadata elements that are given within the MRS, to ensure the quality control of the metadata records in the collection project.

- Development of the metadata system - metadata development task is transferred to metadata system developers according to the MRS and all project teams may need to communicate continually to ensure an effective way of system design.

- Maintenance of metadata service - metadata service model consists of basic elements, including service mechanism that enhances user interface and related function for collection projects and providing consultation in delivering the knowledge of metadata.

- Evaluation of metadata performance - this seeks to evaluate the results of the whole metadata process and performance, including the assessment of metadata record quality and serviceability and the effectiveness of adopting a metadata scheme for retrieval.

In view of metadata provision, digital archives projects often face issues such as how to choose a suitable metadata standard, how to develop metadata specification and how to evaluate a metadata system. The MLM was adopted in this study as it provides a high-level overview of the stages and processes required for successful development and implementation of metadata systems. This model identifies and describes metadata reguirements, potential metadata standards and schemas, metadata strategy formulation, evaluation of potential metadata systems, generation of best practices and guidelines for metadata development. MLM can be used to plan preservation activities in cultural heritage institutions to ensure all necessary stages are undertaken in developing preservation metadata systems. It can also help these institutions with identifying steps and actions which may be required while ensuring processes and policies are adequately documented.

\subsection{Open Archival Information System reference model}

The Open Archival Information System (OAIS) reference model is an important contribution towards shaping an international consensus on the metadata requirements of archived digital objects and consolidating expertise on the use of metadata to support digital preservation (Lavoie 2004). This model provides foundation for developing formal preservation metadata specification and represents a common departure point for different schemes implementation. OAIS model has been extremely influential in developing preservation metadata standards and has been used as framework for digital preservation plans and strategies globally. This model introduces four new categories to the conventional standard metadata structure, namely: reference information, provenance information, context information and fixity information, grouped under the term Preservation Description Information (PDI) (ISO 14721 2002), as illustrated in Figure 2. 


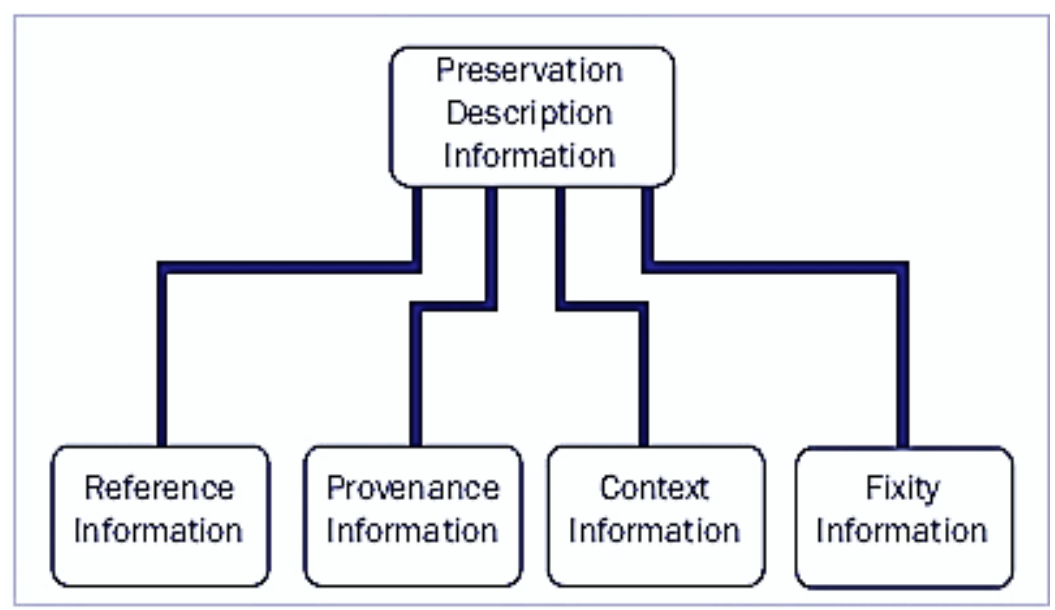

Figure 2: Preservation description information (ISO 14721 2002)

Reference information includes and enumerates specific identifiers assigned to the data, which is referencing such as Uniform Resource Name (URN). Provenance information is used to capture the history of the content information and it helps support a digital object's authenticity and integrity that are important for recordkeeping and publication (ISO 14721 2002). Context information indexes the relationship of the content to its environment while fixity information documents the authentication mechanisms, which will ensure the data is unaltered or show the extent of manipulation (ISO 14721 2002).

This model is invaluable to this study as it facilitates a broader understanding of the preservation requirements and long-term access to digital information. It provides foundation for developing formal preservation metadata and establish a minimum level of functionality for archival repositories, and it highlights the various roles and functions of the designated community's active participants. Technological obsolescence was considered a major issue posing challenges of safeguarding the digital records for long-term keeping. OAIS has the capacity to migrate and provide long-term access to digital information.

\section{Research methodology}

This study adopted a qualitative research approach, a desktop-based research. Literature search on the use of metadata systems in preserving digital records within cultural heritage institutions was conducted using Google Scholar and Scopus database. The search terms and phrases included "digitisation and preservation of digital records in cultural heritage institutions", "metadata systems and digital preservation in cultural heritage institutions", "preservation metadata schemas and standards in cultural heritage institutions". Ngulube (2017) states conducting a literature review can assist to develop a conceptual definition of a construct based on shared meaning and describe what theories were used to explain relationships between concepts. The theories and models on metadata systems application for digital record preservation were reviewed in this study to understand the relationships between concepts and their implications on digital preservation practices and the implementation of metadata systems. 


\section{Findings from literature review}

The findings are discussed in line with the objectives of the study.

\subsection{The use of metadata systems in preserving digital records}

Cultural heritage institutions have managed their information in various analogue formats for centuries, and preserving digital records for the same length of time has become a daunting task. Strategies to support digital preservation processes are vital to enhance access and usefulness of their digital records. Anderson (2004) notes that good digital records management should include policies, guidelines and metadata systems. As a result, emphasis must be placed on preservation policies, strategies and metadata systems in supporting digital environment's many needs. ICA (2016) described metadata as powerful tool to help organisations find, understand and use records to serve multiple purposes, and are needed to track, protect, manage and preserve records. The application of metadata can satisfy digital information resource discovery and use, electronic resources organisation, facilitate interoperability, provide digital information identification, and support archiving and preservation of digital objects (NISO, 2004), which are the most pressing needs of information professionals. Digital records can be uniquely identified, described, retrieved and discovered using appropriate metadata guidelines.

Metadata also contains archival information needed for long-term preservation of the object and migration to other digital formats, as software and hardware change continuously (Groenewald \& Breytenbach 2011). Gilliland-Swetland (2000) concur:

If digital information objects that are currently being created are have a chance of surviving migrations through successive generations of computer hardware and software or removal to entirely new delivery systems, they will need to have metadata that enables them to exist independently of the system that is currently being used to store and retrieve them.

Many cultural heritage institutions recorded different types of metadata information as summarised by ICA (2016). These include:

- Descriptive metadata describing the intellectual entity through properties such as author and title. It supports discovery and delivery of digital content by providing information about where a document comes from, who the creator was, when it was created, where it is located, etc.

- Structural metadata indicating how compound objects are put together and how pages are ordered to form chapters. It captures physical structural relationships, such as which image is embedded in which website, and logical structural relationships such as which page follows which in a digitised book (Dappert \& Enders 2010).

- Administrative metadata providing information to help manage a resource such as when and how it was created and who can access it. It includes provenance information 
of who has cared for the digital object and what preservation actions have been performed on it (Dappert \& Enders 2010).

- Technical or preservation metadata including technical information that applies to any file type, such as information about the software and hardware on which the digital object can be rendered or executed and digital signatures to ensure fixity and authenticity (Dappert \& Enders 2010).

Digital object does not have any meaning unless the content is described with descriptive, structural, administrative and technical metadata. The correct metadata is necessary for any search engine, especially when rich functionality is the goal; after all, content without metadata cannot be easily retrieved (De la Porte \& Higgins 2019). Although all four categories of metadata are essential for digital preservation, this study focused on technical or preservation metadata. All preservation functions depend on the availability of preservation metadata, information describing the digital content in the repository to ensure its long-term accessibility. Preservation metadata is used as strategy to support digital preservation processes to ensure digital objects remain understandable, authentic and identifiable (PREMIS 2005).

\subsection{Digital preservation practices in cultural heritage institutions}

Any society depends on good quality knowledge of its own past and a falsification of that past, whether deliberate or accidental, damages society (Deegan \& Tanner 2006). Therefore, lack of care in preserving digital past and present will ensure cultural heritage institutions have an impoverished digital future. These institutions are traditionally the custodians of valuable artefacts and information and contribute to the preservation of our national cultural heritage. Cultural heritage institutions are committing increasing amounts of time and money to safeguard their digital collections and are engaging in the acquisition and preservation of heritage materials (UNESCO 2003). In South Africa, an increasing number of cultural heritage institutions have already embarked on digitisation to preserve and improve access to their collections (Chisa \& Hoskins 2015). The South African heritage sector embraced digitisation of cultural heritage (Peters, Brenzinger, Meyer, Noble \& Zimmer 2015). Although cultural heritage institutions are digitising and preserving their cultural heritage materials, this may pose challenges in developing countries, such as South Africa. Peters et al. (2015) note that access to South Africa's digital heritage materials may be problematic in the long run due technological, economic, political, legal and moral reasons.

Although cultural heritage institutions have a common mission to make their cultural heritage resources accessible to intended users, libraries have a long history of collecting, storing, organising, preserving and providing access to digital resources. Increasing numbers of libraries have started digitising their unique holdings, including photographs, postcards, books, manuscripts, maps, analogue audio- and video-recordings to enhance long-term access to digital resources. For example, when armed groups occupied Northern Mali and Timbuktu in 2013, librarians smuggled manuscripts to safeguard them and since then, the manuscripts have been kept in the capital and are undergoing restoration and digitisation (Kottoor 2013). After the Earthquake in 2011, libraries from across Japan came together to help rebuild lost infrastructures, safeguard 
and preserve damaged materials (IFLA 2018). Another example is the initiative started by Kanye Public Library in Botswana to capture, record and document cultural events such as cultural day celebrations and provide access to collections of videos and photos (Setshwane \& Oats 2015). Findings of a research by Šalamon-Cindori, Tot and Zivkovic (2017) on 50 European national libraries indicated that almost 94 percent have either digital holdings or a digital library and about half (58 percent) have created virtual exhibitions. Libraries are key partners for any effort to ensure preservation and access to cultural heritage for future generations (IFLA 2018).

Although cultural heritage institutions make digital resources accessible to all, they face different preservation challenges. Tonta (2008) states digital preservation poses more challenges for museums than for libraries and archives. Museums collect 2D and 3D objects, which is challenging since it requires more storage space, special software and high bandwidth to view, while libraries preserve primarily printed and graphic materials (Tonta 2008). Secondly, heritage materials preserved by museums are unique, while library materials usually have more copies kept in different libraries (Tonta 2008). However, cultural heritage institutions face preservation issues as personal papers, which include digital media, are donated to them (Groenewald \& Breytenbach, 2011). These institutions accept the notion that maintaining usable, accessible and sustainable digital collections requires a complex set of actions. Corrado and Moulaison (2014) state the accessibility and usability of content in the digital preservation environment are enhanced through creating and managing preservation metadata. Groenewald and Breytenbach (2011) state that although metadata systems are crucial for preserving the document format and retaining significant properties of a document, and can prevent the loss of digital data in organisations, they are often ignored and have not yet received the same intensity of application to electronic documents.

Richards, Jeffrey and Niven (2013) note that for a digital archive to be considered credible, and thereby attain trusted digital repository status, it must be able to demonstrate well-documented preservation policies and processes and have a robust long-term sustainability plan. Digital preservation policies and procedures document an organisation's commitment to preserve digital content for future use, specify file formats to be preserved, the level of preservation to be provided and ensure compliance with standards and best practices for responsible stewardship of digital information. In South Africa, the legislation contained in the Promotion of Access to Information Act (No. 2 of 2000) require public access to most types of records held at South African Heritage Resource Agency (SAHRA). The National Heritage Resources Act (1999), section 39, stipulates that a record of all conservation-worthy heritage resources must be maintained in the form of a database, which must be publicly accessible and populated in the format prescribed by SAHRA. Cultural heritage institutions should thus make their heritage resources as widely available as possible for access and reuse.

\subsection{Barriers to metadata systems adoption in cultural heritage institutions}

The major challenge faced by cultural heritage institutions is making sure users can access digital content in their digital archives. Although metadata is regarded as suitable strategy to ensure longterm access to digital records, the level of its adoption is low in South African cultural heritage institutions (Groenewald \& Breytenbach 2011) because of lack awareness of metadata systems, 
lack of technical expertise, inadequate funding and lack of technological infrastructure. Cultural heritage institutions face a huge task in adding metadata to different archival sources and in many institutions, lack of qualified personnel and time hinders correct material indexation. Groenewald and Breytenbach (2011) note that negligence with format specifications and use of metadata systems can cause electronic information losses in the future. Metadata systems must be implemented to start successful digital preservation. Studies by Ngulube (2012) and Liebetrau (2012) underscore the enormous preservation challenges faced by most cultural heritage institutions in African countries, including: lack of human capacity and skills, absence of established standards, guidelines, policies, technological obsolescence, lack of collaboration efforts, lack of technological infrastructure, failure to properly assess critical risks related to digital preservation and inadequate administrative metadata. Information professionals, policy developers and other key players in cultural heritage institutions should develop strategies and policies to effectively preserve their digital records.

The rapidly evolving digital technologies impacted the knowledge and skills requirements for information professionals practicing on e-environments (Raju 2014). Adopting metadata systems can pose challenges if information professionals in cultural heritage institutions are not well equipped with technical knowledge and skills to understand and use digital technologies and infrastructures. Corrado and Moulaison (2014) concur that working with digital preservation requires technical skills, researching and understanding trends and being part of an open community supporting long-term access for consumers. According to Raju (2014), many information professionals, librarians and archivists are not comfortable with the digital world they find themselves in, they are technophobic and struggle with how to be stewards of both print and digital information. It is necessary to provide training to information professionals and secure funding for digital preservation projects.

\subsection{Metadata standards used in cultural heritage institutions}

There are several published metadata standards including Preservation Metadata: Implementation Strategies (PREMIS), Metadata Encoding and Transmission Standard (METS), Dublin Core metadata, which have been influential in providing a core set of preservation metadata elements supporting digital preservation processes. These standards encompass all the contextual activities surrounding the archival description, archival material, creator, the functions under which it was produced and the archival repository holding it (Bountouri 2017). Therefore, each institution preparing to preserve its records must develop rules and standards specifically for implementation of metadata systems. Users can create, organise and reuse his own virtual collections and share with others, if metadata standards and interoperability rules are followed (De la Porte \& Higgins 2019). The study focused on preserving specific metadata, namely: PREMIS and METS. These high-level metadata standards provide the much-needed information required to manage and preserve digital records and are based on OAIS model. 


\subsubsection{Preservation metadata: implementation strategies}

OCLC/RLG (2005) developed PREMIS, outlining a set of core elements and strategies for the encoding, storage and management of preservation metadata in a digital preservation system. PREMIS plays a significant role in facilitating preservation decisions, detects preservation threats and provides measures for minimising risks to long-term access to digital information (Alemneh, Hastings \& Hartman 2002). The two objectives of PREMIS were to develop a core preservation metadata set supported by a data dictionary, and identify and evaluate alternative strategies for encoding, storing and managing preservation metadata in digital preservation systems (PREMIS 2005).

PREMIS defines a common data model for organising preservation metadata and supports specific implementations through guidelines for their management and use, and emphasises enabling automated workflows. The PREMIS data model describes five elements associated with digital preservation processes: intellectual entity, objects, rights, agents and events (PREMIS 2005). The research conducted by other cultural heritage institutions such as the national libraries of Australia, New Zealand, Great Britain and the Netherlands greatly inform the development of the PREMIS model that became the international de facto standard for preservation metadata (Caplan 2006).

\subsubsection{Metadata encoding and transmission standard}

Metadata Encoding and Transmission Standard (METS) is the standard for exchanging and storing metadata independent of specific project needs. It was created to fill the metadata gap that existed, and it can wrap any metadata for all kinds of digital objects such as electronic text, digital images, digital video- and audio-visual materials (Library of Congress 2016). METS includes the following components, as summarised by Library of Congress (2016):

- METS header which provides the metadata of a document such as creator, date of creation, and others.

- Descriptive metadata giving links to external descriptive metadata records (i.e. XML and PDF).

- Administrative metadata, which can be external or embedded in the METS document, provides technology metadata, rights metadata, analogue or digital resources metadata and digital provenance metadata.

- File section which defines the content files of the digital object.

- Structural map which allows the hierarchical organisation of the content files of a digital object described in a file section.

- Structural links which defines the links between the different components of a METS structure as they have been structured in a structural map.

\section{Conclusion and recommendations}

Many cultural heritage institutions recognised the importance of metadata as key enabler of the digital preservation processes, resulting in them in-house metadata schemas and standards. However, there was no awareness of metadata systems and standards, although they have been 
adopted to enable description, discovery, delivery and preservation of digital records. Cultural heritage institutions should promote awareness programmes by providing short-term courses, inhouse training programmes, workshops, seminars, and others. For effective digital preservation, cultural heritage institutions must develop strategies to overcome obstacles such as ever-changing digital technology or technology obsolescence. Other recommendations pointing to the adoption of metadata systems include the enactment of preservation policies, global standards, regulations and more collaborative opportunities. Cultural heritage institutions should continue building consultation networks with various stakeholders for best practices. Collaborative efforts such as the Digital Preservation Coalition, the International Research on Permanent Authentic Records in Electronic Systems (InterPARES), the Data Archiving and Networked Services (DANS), just to name a few, brought together archival scholars, national archival institutions and the private industry collaborating to formulate policies, strategies and standards for long-term preservation of authentic records created in electronic systems. By collaborating with other institutions, cultural heritage institutions would be exposed to new ideas and strategies to successfully preserve their digital records. Collaboration can also make core services more convenient for users, reduce the workload for individual institutions and increase standardisation of policies and digital platforms. A clear framework serving as useful guide in the preservation of digital resources within these institutions must be be implemented.

\section{References}

Alemneh, D. Hastings, S., \& Hartman, C. 2002. A Metadata Approach to Preservation of Digital Resources: The University of North Texas Libraries Experience. First Monday 7(8).

Anderson, W.L. 2004. Some challenges and issues in managing and preserving access to long live collections of digital scientific and technical data. Data Science Journal 3:191202.

Boamah, E. 2014. Towards effective management and preservation of digital cultural heritage resources: an exploration of contextual factors in Ghana. Victoria University of Wellington: New Zealand.

Bountouri, L. 2017. Archives in the digital age: standards, policies and tools. United Kingdom: Chandos.

Brungs, J. \& Wyber, S. 2016. Preserving our digital culture for the future: overcoming obstacles through collaboration. International Federation of Library Associations and Institutions (IFLA). Global Information Society Watch.

Chowdhury, G. 2009. From digital libraries to digital preservation research: The importance of users and context. Journal of Documentation 66(2):207-223.

Chen, Y., Chen, S. \& Lin, S.C. 2003. A metadata lifecycle model for digital libraries: methodology and application for an evidence-based approach to library research. World Library and Information Congress: 69th IFLA General Conference and Council 1-9 August 2003, Berlin.

Chisa, K. \& Hoskins, R. 2015. Decolonising indigenous intellectual and cultural rights in heritage institutions: a survey of policy and protocol in South Africa. Mousaion 33(3):55-72.

Corrado, E.M. \& Moulaison, H.L. 2014. Digital preservation for libraries, archives, and museums. Lanham: Rowman \& Littlefield. 
Council of Canadians Academies. 2015. Leading in the digital world: opportunities for Canada's memory institutions. The expert panel on memory institutions in the digital revolution. Council of Canadian Academies, Ottawa.

Dappert, A. \& Enders, M. 2010. Digital preservation metadata standards. Information Standards Quarterly (ISQ) 22(2).

Dar, B.A. \& Ahmad, S. 2017. Recent trends in digital archiving and preservation: a global perspective. Raleigh: Laxmi Book Publication.

Deegan, M. \& Tanner, S. 2006. Key issues in digital preservation. In Deegan, M. \& Tanner, S. (eds.). Digital preservation. London: Facet.

De la Porte, B. \& Higgs, R. 2019. Challenges in digitization of cultural heritage material in the Western Cape, South Africa. South African Journal of Information Management 21(1).

Duranti, L. 2010. The long-term preservation of the digital heritage: a case study of universities' institutional repositories. JLIS.it. 1(1):157-168.

Duranti, L., Rogers, C., Mcleod, J. \& Shepherd, E. 2019. Trusting records and data in the cloud: the creation, management, and preservation of trustworthy digital content. London: Facet.

Gilliland-Swetland, A. 2000. Setting the stage. Getty Research Institute.

Groenewald, R. \& Breytenbach, A. 2011. The use of metadata and preservation methods for continuous access of digtal data. University of Pretoria, South Africa.

Ilo, P.I. 2015. Acquisition, preservation and accessibility of indigenous knowledge in academic libraries in Nigeria: the place of ICT. Ikenga: International Journal of Institute of African Studies 14(1):468-487.

Kalusopa, T. 2018. Preservation and access to digital materials: strategic policy options for Africa. In Ngulube, P. (ed.). Handbook of research on heritage management and preservation. IGI: Global, 150-170.

Kalusopa, T. \& Zulu, S. 2009. Digital heritage material preservation in Botswana: problems and prospects. Collection Building 28(3):98-107.

Kanyengo, C.W. 2009. Managing digital information resources in Africa: Preserving the integrity of scholarship. The International Information \& Library Review 41(1):34-43.

Kottoor, N. 2013. How Timbuktu's manuscripts were smuggled to safety. BBC Magazine. Available at: https://www.bbc.com/news/magazine-22704960 (accessed 4 June 2013).

Lavoie, B.F. 2004. The incentives to preserve digital material: Roles, scenarios and economic decision-making. White Paper.

Library of Congress. 2016. Metadata Encoding and Transmission Standards (METS): Documentation.

Liebetrau, P. 2012. Preserving our heritage: an independent advantage. The memory of the world in the digital age: an international conference on permanent access to digital documentary heritage. Canada.

Masenya, T.M. 2018. A framework for preservation of digital resources in academic libraries in South Africa. PhD thesis, University of South Africa.

May, J. 2010. Digital and other poverties: exploring the connection in four East African countries. University of KwaZulu-Natal, South Africa. 
National Archives and Records Service of South Africa (NARS). 2006. Managing electronic records in governmental bodies: policy, principles and requirements. Department of Arts and Culture: South Africa.

Ngulube, P. 2012. Ghosts in our machines: preserving public digital information for the sustenance of electronic government in sub-Saharan Africa. Mousaion: South African Journal of Information Studies 30(2):127-135.

Ngulube, P. 2017. Overcoming the difficulties associated with using conceptual and theoretical frameworks in heritage studies. In Ngulube, P (eds.). Handbook of research on heritage management and preservation. Hershey: IGI Global.

OCLC \& CRL. 2007. Trustworthy Repository Audit \& Certification: Criteria \& Checklist (accessed 16 April 2012).

Peters, D., Brenzinger, M., Meyer, R., Noble, A. \& Zimmer, N. 2015. The digital library in the reinscription of African cultural heritage. International Federation of Library Associations and Institutions (IFLA) 41(3):204-210.

PREMIS Working Group. 2005. Data dictionary for preservation metadata: final report of the PREMIS working group, version 1.0. (accessed 7 August 2014).

Ross, S. \& Hedstrom, M. 2005. Preservation research and sustainable digital libraries. International Journal of Digital Libraries 5(4).

Rosenthal, D.S.H., Robertson, T., Lipkis, T., Reich, V. \& Morabito, S. 2005. Requirements for digital preservation systems: a bottom-up approach. D-Lib Magazine 11(11).

Šalamon-Cindori, B., Tot, M. \& Zivkovic, D. 2017. Digitization: Challenges for Croatian Museums. Qualitative and Quantitative Methods in Libraries 3 (1): 213-220.

Sambo, A.S., Urhefe, E.A. \& Ejitagha, S. 2017. A survey of digital preservation challenges in Nigerian libraries: librarians' perspective. International Journal of Curation 12(1):117128.

Setshwane, C.M. \& Oats, L. 2015. Cultural preservation through public libraries: Lessons from Kanye Public Library. Satellite Meeting: References and Information services, 11-13 August. University of Botswana, Gaborone.

Simpson, D. 2004. Risk of loss of digital data and the reasons it occurs: Case studies and analysis. DPC data loss. United Kingdom.

Sigauke, D.T. \& Nengomasha, C.T. 2011. Challenges and prospects facing the digitization of historical records for their preservation with national archives of Zimbabwe. 2nd International Conference in African Digital Libraries and Archives. South Africa: University of Witwatersrand.

Styblinska, M. 2006. Long-term preservation of digital assets: some specific aspects. In Proceedings of the International Multiconference on Computer Science and Information Technology Available at: https://www.yumpu.com/en/document/view/33742324/long-term-preservation-ofdigital-assets-some-specific-aspects (accessed 10 November 2015).

Raju, J. 2014. Knowledge and skills for the digital era academic library. The Journal of Academic Librarianship 40:163-170.

Richards, J.D., Jeffrey, S. \& Niven, K.2013. Preserving our Digital Heritage: Information Systems for data management and preservation. In Ch'ng, E \& Gaffney, V (eds). Visual Heritage in the Digital Age. Springer-Verlag. 311-326. 
Tonta, Y. 2008. Libraries and museums in the flat world: Are they becoming virtual destinations? Library Collections, Acquisitions \& Technical Services 32(1): 1-9.

UNESCO. 2003. Convention for the safeguarding of the intangible cultural heritage, Paris. Available at: http://unesdoc.unesco.org/images/0013/001325/132540e.pdf (accessed 09 February 2016).

UNESCO. 2010. Managing disaster risks for world heritage. Available at: http://www.preventionweb.net/files/14614_188562e1.pdf. (accessed 09 February 2016).

UNESCO. 2012. The memory of the world in the digital age: digitization and preservation held from 26 to 28 September 2012. Vancouver, British Columbia: Canada. 